\title{
Antibodies to extractable nuclear antigens. Has technological drift affected clinical interpretation?
}

\author{
R J Lock, D J Unsworth
}

\begin{abstract}
Precipitating antibodies to extractable nuclear antigens are important in the diagnosis of connective tissue diseases. Disease associations are defined using gel based techniques. Alternative technologies have been introduced, including passive haemagglutination, enzyme linked immunosorbent assay, and western blotting. This leader contains a review of the literature on the clinical usefulness of these assays, together with knowledge gained from personal experience. Using the example of systemic lupus erythematosus, the sensitivity, specificity, and positive predictive value of the assays for disease is discussed, as is their differences in performance. The conclusion drawn is that disease specificity is method dependent. Validation and audit of performance of the method selected by the investigation laboratory is essential. (F Clin Pathol 2001;54:187-190)
\end{abstract}

Keywords: extractable nuclear antigen; gel precipitation; enzyme linked immunosorbent assay

Precipitating antibodies to extractable nuclear antigens (ENA) have been widely used as diagnostic tools in connective tissue disease since their discovery over four decades ago. ${ }^{1}$ The early work $^{23}$ relied on immunoprecipitation techniques (double diffusion or counter current immunoelectrophoresis (CIE)). The disease associations we understand today were originally defined using these gel based techniques. ${ }^{4}$ For example, the specificity of anti-Sm antibodies for systemic lupus erythematosus (SLE) in CIE is very high and as a result the presence of anti-Sm is one of the American Rheumatism Association (ARA) diagnostic criteria for SLE. ${ }^{5}$ When viewing the data given below it is important to note the distinction between the ability of the test to detect the antibody when present (the assay sensitivity) and the frequency with which the antibody occurs in a given disease (disease sensitivity). Gel precipitation assays have some limitations (see below). Therefore, several other approaches have been explored, with the aim of increasing assay sensitivity but without a loss of disease specificity. Passive haemagglutination, enzyme linked immunosorbent assay (ELISA), and western blotting (WB) have all been advocated as alternative methods for use in diagnostic laboratories. Here, we review the literature on the clinical usefulness of these assays, together with our own experience.
Gel precipitation assays

Gel precipitation remains the reference method $^{6}$ and, even now, the major specificities are still defined using reference precipitating antibodies from the Centres for Disease Control (CDC). They are not quantitative and disease sensitivity is poor. For example, only $8-40 \%$ of patients with SLE have detectable anti-Sm by these methods. CIE has been shown in several studies to be more sensitive than double diffusion. ${ }^{7}$ It should be noted that some of this variation in disease sensitivity is determined by ethnic origin, with a higher incidence of anti-Sm seen in American blacks with SLE than in whites. ${ }^{89}$

\section{Passive haemagglutination}

There have been comparatively few studies using passive haemagglutination. ${ }^{10-12}$ Analysis appears to have been restricted to anti-Sm and anti-ribonuclear protein (RNP) antibodies. Although assay sensitivity is high, some problems with specificity, in particular with differentiating anti-Sm from anti-U1-RNP, have been described. ${ }^{11}$ In contrast, Hamburger and colleagues ${ }^{13}$ found anti-Sm to be $100 \%$ specific for SLE. The method was quite popular in the late 1970 s but has since been superseded by ELISA.

\section{Enzyme linked immunosorbent assay}

Many ELISA systems have been developed ${ }^{14-16}$ and several are commercially available. These assays have some practical advantages. They are simple to perform, quantitative, and offer high throughput volume. ELISA is becoming the most widely used method, with over $50 \%$ of laboratories registered with the UK National External Quality Assessment Schemes (UK NEQAS) using ELISA alone as the method of analysis. In addition, many laboratories use ELISA in combination with other tests. A large number of different ELISA methods are available with 21 manufacturers being represented in UK NEQAS.

In reviewing the literature, the poorer nature of some of the historical data should be noted. There are, however, some important illustrative points. Although assay sensitivity is often increased this can be at the cost of decreased disease specificity ${ }^{17}$ and it may be that these assays are too sensitive for routine analysis. Because of its inclusion in the ARA diagnostic criteria, it is of particular concern that anti-Sm antibodies have been reported in patients without SLE. ${ }^{5}$ The positive predictive value for SLE of anti-Sm was only $51 \%$ in one early study. ${ }^{16}$ However, this has not been a universal finding ${ }^{9}$ and probably results in part from the quality of 
Table 1 Reactivity of Centres for Disease Control (Atlanta, Georgia, USA) prototype sera in six detection systems for anti-Ro, anti-La, anti-Sm, and anti-U1-RNP

\begin{tabular}{lllllll}
\hline & \multicolumn{2}{l}{ Method } & & & & \\
\cline { 2 - 6 } Prototype serum & CIE-IH & CIE-Com & ELISA-1 & ELISA-2 & ELISA-3 & WB-Com \\
\hline Anti-Ro & Ro & Ro & Ro & Negative & Ro & Negative \\
Anti-La & La & La & Ro + La & La & Ro + La & La \\
Anti-Sm & Sm & Sm & Sm/RNP & Sm/RNP & Sm/RNP & Sm \\
Anti-U1-RNP & RNP & RNP & RNP & RNP & RNP & RNP \\
\hline
\end{tabular}

Results are expressed as those specificities detected in each prototype serum.

ELISAs 1,2, and 3 are from different manufacturers.

CIE-Com, countercurrent immunoelectrophoresis (commercial); CIE-IH, countercurrent immunoelectrophoresis (in house); ELISA, enzyme linked immunosorbent assay; RNP, ribonuclear protein; WB-Com, western blotting (commercial).

Table 2 Comparison of screening methods

\begin{tabular}{llllll}
\hline & CIE-IH & CIE-Com & ELISA-1 & ELISA-2 & WB-Com \\
\hline Normal blood donors $(\mathrm{n}=100)$ & 2 & 1 & 11 & 1 & Not tested \\
Normal pregnancy $(\mathrm{n}=115)$ & 1 & 0 & 0 & 1 & $7(\mathrm{n}=60)$
\end{tabular}

Values are the number of positives detected in each category in sera from two groups without connective tissue disorders.

Both ELISA systems contained six antigens: Ro, La, Sm, U1-RNP, Scl70, and Jo-1.

Positive samples were subsequently negative using CIE and specific ELISAs for the individual antigens.

CIE-Com, countercurrent immunoelectrophoresis (commercial); CIE-IH, countercurrent immunoelectrophoresis (in house); ELISA, enzyme linked immunosorbent assay; RNP, ribonuclear protein; WB-Com, western blotting (commercial).

antigen source used (partially purified, purified, or recombinant). Although the second multicentre European study showed that ELISA methods are improving, ${ }^{7}$ the recent study of Bizzaro et al suggests that the problem of false positive results in ELISA is still widespread. ${ }^{18}$ This is further highlighted by the suggestion in an older study that many paraproteins also have anti-Sm activity, ${ }^{19}$ although again this is disputed. ${ }^{20}$ In the first multicentre European study ${ }^{21}$ many in house ELISAs performed badly. This was attributed to the inadequate purification of antigen and poor choice of blocking reagents and conjugates. ELISA may miss anti-Ro (table 1), even when using the prototype CDC reference sera. This is probably a result of the vigorous antigen preparation methods. It has been shown that some sera react only with conformational antigens $^{22} 23$ and perhaps these can also be missed by ELISA. In addition, it has been shown that some sera contain antibodies that are species specific and react only with human $\mathrm{Ro},{ }^{24}$ but this would affect all detection methods.

The introduction of ELISA "screening assays" has been popular but has its drawbacks. Multiple antigens are coated on to microtitre plates, usually a combination of Ro, La, Sm, and U1-RNP, with many also including Jo-1 and Scl70. We and others ${ }^{25}$ have found that these are not always optimised (table 2). In the analysis of normal control sera 11 of 100 blood donors were positive by screening ELISA-1. However, these were all admittedly shown to be negative for anti-Ro, anti-La, anti-Sm, and anti-U1-RNP, both in CIE and by specific ELISAs. False positive initial screening raises the spectre of autoimmune disease in an otherwise healthy individual and the risk of over investigation. Unnecessary typing (subsequently negative) and repeat analyses are also time consuming and costly. We do not wish to suggest that all screening ELISAs are problematical, but would emphasise that problems can occur and that laboratories need to undertake local evaluations to ensure quality.

\section{Western blotting}

Immunoblotting was introduced in the 1980 s and has been useful in refining our understanding of the spectrum of anti-ENA, in particular, the dissection of anti-Ro reactivity ${ }^{26}$ into $60 \mathrm{kDa}$ and $52 \mathrm{kDa}$ subsets (indistinguishable by immunoprecipitation). Again, a major disadvantage with this technique is that antibodies directed against conformational epitopes are not detected..$^{22}$ In several studies, immunoblotting was found to be particularly insensitive for anti-Ro. ${ }^{712728}$ This apparent paradox is explained by the fact that the higher resolution seen in WB detects only linear epitopes, whereas some $15 \%$ of anti-Ro antibodies react only with conformational epitopes not detectable in WB. In the European studies, ${ }^{721}$ a major problem was found to be the use of nuclear extracts from which Ro leaches easily. Furthermore, Ro was considered a poor "blotter". Commercial versions are available where pre-run and blotted strips are used. These are considerably easier to perform than in house assays but the sensitivity to anti-Ro is still questionable. In our hands, we found the CDC prototype anti-Ro serum to be unreactive (table 1). This mirrors the experience of the ANA subcommittee of the standardisation committee of the International Union of Immunological Societies. ${ }^{29}$ In addition, a recent study has suggested that immunoblotting is inadequate for anti-Scl70, with an assay sensitivity of only $25 \% .{ }^{18}$ Lerma et al identified a problem with the under detection of U1-RNP. ${ }^{28}$ This was confirmed in our own hands where a commercial WB assay detected only 21 of 28 sera containing anti-RNP antibodies, which could be detected by both CIE and ELISA. Again, disease specificity is poor and in studies on normal populations false positives are not infrequent. De Vlam et al found 18 of 485 healthy blood donors positive and we found seven of 60 normal pregnant women positive (table 2 ).$^{30}$ More recently, dot blot methods have been introduced, ${ }^{31}$ which offer the possibility of better antigen integrity. Commercial versions are available, but we have no experience of these.

\section{Which is the best method?}

Table 3 summarises the advantages and disadvantages of the various assays discussed above. In table 4 we have analysed those few studies that are both sufficiently large and sufficiently detailed to offer data for the derivation of disease sensitivity, disease specificity, and positive predictive value (PPV) of anti-ENA in the context of SLE (our own data are not included). These confirm the low disease sensitivity and high specificity of gel diffusion techniques for a diagnosis of SLE. In house ELISAs are very variable in their performance and the low PPV seen in some for anti-Sm is worrying. A few studies using commercial ELISAs have been published and these appear to be more reliable than in house versions. 
Table 3 Advantages and disadvantages associated with the methods used to detect antibodies to extractable nuclear antigens

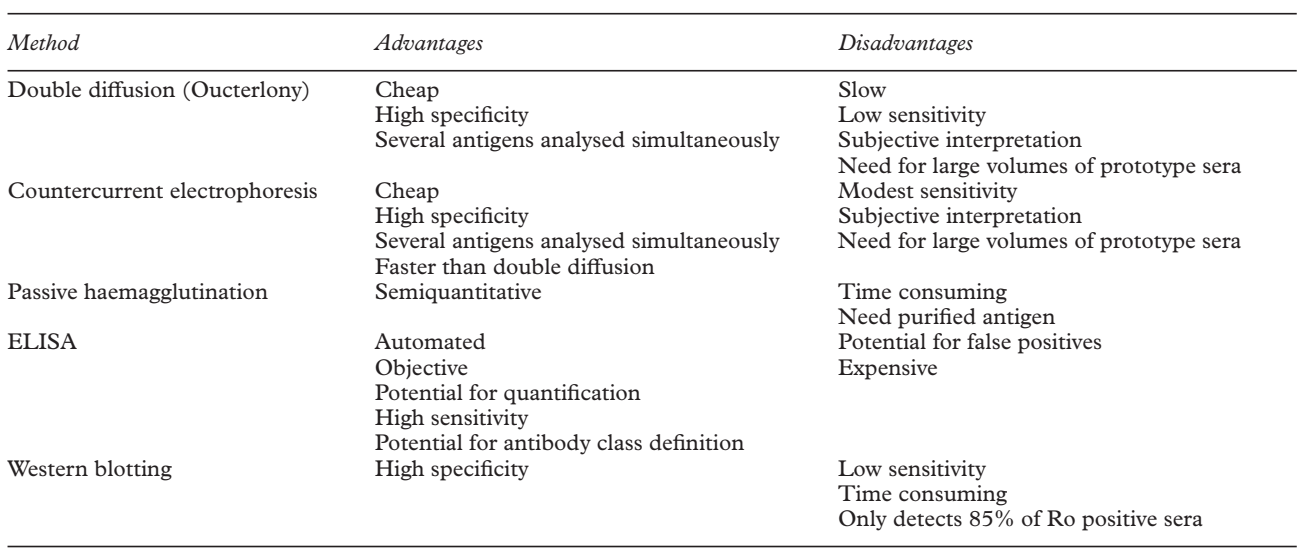

ELISA, enzyme linked immunosorbent assay.

Table 4 Disease sensitivity, specificity, and positive predictive value (PPV) of various methods for the analysis of Ro, La, Sm, and U1-RNP for a diagnosis of systemic lupus erythematosus ${ }^{91012162832-36}$

\begin{tabular}{llll}
\hline Anti-Ro & Sensitivity & Specificity & $P P V$ \\
\hline Double diffusion & 33 & 97 & 84 \\
CIE & 29 & 99 & 64 \\
ELISA (in house) & 55 & 85 & 59 \\
ELISA (commercial) & 61 & $80-93$ & $75-91$ \\
Anti-La & & & \\
Double diffusion & 15 & 99 & 90 \\
CIE & 14 & 99 & 81 \\
ELISA (in house) & 24 & 85 & 39 \\
ELISA (commercial) & $27-35$ & $88-97$ & $73-90$ \\
Anti-Sm & & & \\
Double diffusion & $17-35$ & $99-100$ & $89-100$ \\
CIE & $11-56$ & $98-100$ & $90-100$ \\
ELISA (in house) & $19-33$ & $87-100$ & $12-100$ \\
ELISA (commercial) & $34-45$ & $88-100$ & $73-100$ \\
Anti-U1-RNP & & & \\
Double diffusion & $17-30$ & $87-99$ & $31-90$ \\
CIE & $8-35$ & $83-99$ & $37-57$ \\
ELISA (in house) & $4-46$ & $91-98$ & $11-67$ \\
ELISA (commercial) & $39-64$ & $84-97$ & $70-95$ \\
\hline
\end{tabular}

All figures expressed as percentages.

CIE, countercurrent immunoelectrophoresis; ELISA, enzyme linked immunosorbent assay; RNP, ribonuclear protein.

\section{Antigen source}

Laboratory workers need to be aware of the advantages and disadvantages of the available materials. Foremost is the need for a good antigen source. Some commercial preparations might lack sufficient amounts of important antigens. ${ }^{37}$ For diffusion techniques the most frequently quoted antigen sources are calf thymus, rabbit thymus, rabbit spleen, and human spleen. Human spleen is reputed to be a better source of Ro antigen than the alternatives. However, clinical governance concerns are expected to limit the availability of human material. Our own practice is to use commercial acetone powders of calf and rabbit thymus (Biogenesis), with the former proving to be an adequate source of Ro. ELISAs can use either purified or recombinant antigens. The former might suffer from degradation in preparation, whereas the latter still have some problems with respect to the detection of anti-Ro and anti-U1-RNP. ${ }^{28}$ As discussed above, antibody binding to some epitopes, particularly for Ro, appears to be highly dependent on conformation.

\section{Discussion}

Availability and technical simplicity have made ELISA products popular (an "off the shelf" culture). However, we suspect that in many cases this has been undertaken without a full appreciation of the differences in disease sensitivity and disease specificity and without informing the relevant users, largely rheumatologists. Although understandable, this might provide a disservice to the clinician who is used to the old disease associations. It is crucial to ensure that the laboratory and the clinician are both tuned in to the same assay.

It must be appreciated that ELISA and immunoblotting techniques are more likely to detect low affinity antibodies than the gel diffusion methods. The clinical relevance of these is incompletely understood. In view of the problems with anti-Ro detection in immunoblotting this should not be used alone. ELISAs too have some potential problems in that the purification procedures for the antigens might be very vigorous and potentially denaturing. Hence, ELISAs might also be unreliable in detecting certain conformational epitopes. The different systems (gel precipitation, ELISA, and WB) thus detect different, overlapping subsets of the antibodies available in a given serum. This being so, the disease associations found by one method might not be corroborated by another, leading to the conclusion that disease specificity is method dependent.

\section{Recommendations}

The European study ${ }^{21}$ recommends that, if possible, two different methods should be used to assign specificity to a serum. Unfortunately, this commendable idea is unlikely to be widely applied owing to financial and manpower restraints.

To select the most reliable and cost effective assay(s) from those available is a daunting task. The aim is technical reliability (a reproducible assay) with the best disease sensitivity and specificity. It is a mistake to rely on secondary information, including the manufacturer's own data. It is therefore the responsibility of the investigating laboratory to verify the specificity and sensitivity of the method it selects for local 
use. To this end, the use of standard reference sera (CDC or WHO, Dutch Red Cross) to validate assays is mandatory.

Finally, it is crucial to inform users of any change in service provision and to audit those changes in a prospective study.

1 Holman HR, Deicher HR, Kunkel HG. The LE cell and the LE serum factors. Bull N Y Acad Med 1959;35:409-18.

2 Clark G, Reichlin M, Tomasi TB, Jr. Characterization of soluble cytoplasmic antigen reactive with sera from patients
with systemic lupus erythematosus. $\mathcal{F}$ Immunol $1969 ; 102$ : 107-22.

3 Tan EM, Kunkel HG. Characteristics of a soluble nuclear antigen precipitating with sera of patients with systemic lupus erythematosus. F Immunol 1966;96:464-71.

4 Tan EM, Fritzler MJ, McDougal JS, et al. Reference sera for antinuclear antibodies. I. Antibodies to native DNA, Sm, nuclear RNP, and SS-B/La. Arthritis Rheum 1982;25:10035 .

5 Tan EM, Cohen AS, Fries JF, et al. The 1982 revised criteTan EM, Cohen AS, Fries JF, et al. The 1982 revised crite-
ria for the classification of systemic lupus erythematosus. ria for the classification of systen
Arthritis Rheum 1982;25:1271-7.

6 Isenberg DA, Maddison PJ. Association of Clinical Pathologists Broadsheet 117. Detection of antibodies to double stranded DNA and extractable nuclear antigen. $f$ Clin Pathol 1987;40:1374-81.

7 Charles PJ, van Venrooij WJ, Maini RN, and the Consensus Finding Group for Autoantibodies. The consensus workshops for the detection of autoantibodies to intracellular antigens in rheumatic diseases: 1989-1992. Clin Exp Rheumatol 1992;10:507-11.

8 Arnett FC, Hamilton RG, Roebber MG, et al. Increased frequencies of Sm and nRNP autoantibodies in American blacks compared to whites with systemic lupus erythematosus. F Rheumatol 1988;15:1773-6.

9 Field M, Williams DG, Charles P, et al. Specificity of anti-Sm antibodies by ELISA for systemic lupus erythematosus: increased sensitivity of detection using purified peptide antigens. Ann Rheum Dis 1988;47:820-4

purified peptide antigens. Ann Rheum Dis 1988;47:820-4.
10 Notman DD, Kurata N, Tan EM. Profiles of antinuclear Notman DD, Kurata N, Tan EM. Profiles of antinuclear
antibodies in systemic rheumatic diseases. Ann Intern Med 1975;83:464-9.

11 Siracusano A, Agelli M, Ioppolo S, et al. Detection of antiextractable nuclear antigens in connective tissue diseases: comparison between passive haemagglutination, counterimmunoelectrophoresis and double immunodiffusion. Ric Clin Lab 1985;15:33-8.

12 McCain GA, Bell DA, Chodirker WB, et al. Antibody to extractable nuclear antigen in the rheumatic diseases. $\mathcal{F}$ Rheumatol 1978;5:399-406.

13 Hamburger M, Hodes S, Barland P. The incidence and clinical significance of antibodies to extractable nuclear antigens. Am ₹ Med Sci 1977;273:21-8.

14 Venables PJW, Charles PJ, Buchanan RR, et al. Quantitation and detection of isotypes of anti-SS-B antibodies by ELISA and Farr assays using affinity purified antigen. Arthritis Rheum 1983;26:146-55.

15 Yagamata H, Harley JB, Reichlin M. Molecular properties of the Ro/SSA antigen and enzyme-linked immunosorbent of the Ro/SSA antigen and enzyme-linked immunosorbent assay for

16 Maddison PJ, Skinner RP, Vlachoyiannapoulos P, et al. Antibodies to nRNP, Sm, Ro(SSA) and La(SSB) detected by ELISA: their specificity and inter-relations in connective tissue disease sera. Clin Exp Immunol 1985;62:337-45.

17 Meilof JF, Bantjes I, De Jong J, et al. The detection of antiRo/SS-A and anti-La/SS-B antibodies. A comparison of counterimmunoelectrophoresis with immunoblot, ELISA and RNA-precipitation assays. $\mathcal{F}$ Immunol Methods 1990 133:215-26.
18 Bizzaro N, Tozzoli R, Tonutti E, et al. Variability between methods to determine ANA, anti-dsDNA and anti-ENA industry. F Immunol Methods 1998;219:99-107.

19 Abu-Shakrah M, Krupp M, Argov S, et al. The detection of anti-Sm-RNP activity in sera of patients with monoclonal gammopathies. Clin Exp Immunol 1989;75:349-53.

20 Hardiman KL, Horn S, Manoharan A, et al. Rheumatic antibodies in the sera of patients with paraproteins. Clin Exp Rheumatol 1994;12:363-8.

21 van Venrooij WJ, Charles P, Maini RN. The consensus workshops for the detection of autoantibodies to intracellu1991;140:181-9.

22 Boire G, Lopez-Longo F-J, Lapointe S, et al. Sera from patients with autoimmune disease recognize conformational determinants on the $60-\mathrm{kd}$ Ro/SS-A protein. Arthritis Rheum 1991;34:722-30.

23 Itoh Y, Itoh K, Frank MB, et al. Autoantibodies to the Ro/SSA autoantigen are conformation dependent. I: Anti-60kD Ro/SSA antibodies are mainly directed to the native protein; anti-52kD antibodies are directed to the denatured protein. Autoimmunity 1992;14:89-95

24 Reichlin M, Radar M, Harley JB. Autoimmune response to the Ro/SSA particle is directed to the human antigen. Clin Exp Immunol 1989;76:373-7.

25 Van Duijnhoven HL, Van de Warenburg FJ, Willems RJ, et al. A comparison of ELISA assays as routine diagnostic test for detection of autoantibodies against extractable nuclear antigens. Clin Biochem 1999;32:179-83.

26 Ben-Chetrit E, Chan EKL, Sullivan KF, et al. A 52-kD protein is a novel component of the SS-A/Ro antigenic particle. F Exp Med 1988;167:1560-71.

27 Ben-Chetrit E, Fox RI, Tan EM. Dissociation of immune responses to the SS-A (Ro) 52-kd and 60-kd polypeptides in systemic lupus erythematosus and Sjögren's syndrome. Arthritis Rheum 1990:33:349-55.

28 Lerma JGG, Mendoza AZ, Ramos MJ, et al. Evaluation of recombinant Ro/SSA, La/SSB, Sm and U1 RNP autoantigens in clinical diagnosis. F Clin Lab Anal 1995;9:52-8.

29 Smolen JS, Butcher B, Fritzler MJ, et al. Reference sera for antinuclear antibodies. II. Further definition of antibody specificities in international antinuclear antibody reference sera by immunofluorescence and western blotting. Arthritis Rheum 1999;40:413-18.

30 De Vlam K, De Keyser F, Verbruggen G, et al. Detection and identification of antinuclear autoantibodies in the serum of normal blood donors. Clin Exp Rheum 1993;11: 393-7.

31 Ermens AA, Bayens AJ, van Gemart AC, et al. Simple dotblot method evaluated for detection of antibodies against extractable antigens. Clin Chem 1997;43:2420-2.

32 Sulcebe G, Morcka K. Diagnostic and prognostic significance of different antinuclear antibodies in more than 1000 consecutive Albanian patients with rheumatic diseases. Clin Exp Rheumatol 1992;10:255-61.

33 Sánchez-Guerrero J, Lew RA, Fossel AH, et al. Utility of anti-Sm, anti-RNP, anti-Ro/SS-A, and anti-La/SS-B (extractable nuclear antigens) detected by enzyme-linked immunosorbent assay for the diagnosis of systemic lupus erythematosus. Arthritis Rheum 1996;39:1055-61.

34 Zimmermann-Górska I, Potocka-Michajluk U. Comparative evaluation of various methods of detecting antibodies against soluble nuclear antigens. Arch Immunol Ther Exp (Warsz) 1982;30:89-94.

35 Bresnihan B, Bunn C, Snaith ML, et al. Antiribonucleoprotein antibodies in connective tissue diseases: estimation by counterimmunoelectrophoresis. BMF 1977;1:610-11.

36 Struckman J, Worning P, Manthorpe R et al. Detection of antibody against extractable nuclear antigen by an enzymelinked immuno-sorbent assay. Allergy 1985;40:442-6.

37 White PJ, Hoch SO. Definition of the antigenic polypeptides in the Sm and RNP ribonucleoprotein con 